\title{
Medianstellung des linken Stimmbandes, Stenose der Trachea, Aneurysma der Aorta, Durchbruch der Luftröhre.
}

Von Prof. Dr. A. Ónodi, Direktor der rhinolaryngologischen Universitätsklinik in Budapest.

Mit 2 Abbildungen.

Es handelte sich um eine 57jährige Frau, die am I8. März IgI6 in die Klinik wegen Atembeschwerden aufgenommen wurde. Sie klagte über schmerzhaften Husten und Atembeschwerden, welche vor 3 Monaten aufgetreten sind. Die laryngoskopische Untersuchung zeigt das linke Stimmband in der Medianstellung. Wegen den starken Atembeschwerden mußte sogleich die Tracheotomie ausgeführt werden. Die Einführung der Kanüle beseitigte nicht die Atembeschwerden, dieselben schwanden erst nach Einführung der Königschen Kanüle. Die klinische Untersuchung gab folgende Diagnose: Insufficientia aortae, Stenosis ostii atr. sin., Aneurysma arcus aertae. Der Röntgenbefund lautete: Herzschatten nach links und nach unten bedeutend vergrößert. AnschlieBend zum Mittelschatten des Aortenbogens ist ein fast faustgroßer pulsierender Schatten vorhanden. Eine Woche später ist eine letale Blutung eingetreten. Die Sektion zeigte ein hühnereigroßes enghalsiges Aneurysma am obersten Teil der Aorta descendens, welches das Rückgrat, den vorderen Teil des dritten Halswirbels usurierte, ferner knapp oberhalb der Bifurkation mit einer $3 \mathrm{~cm}$ langen und $\mathrm{I} 1 / 2 \mathrm{~cm}$ breiten Öffnung die Luftröhre perforierte. Es war eine Mesarteritis luetica der Aorta vorhanden.

Der klinische Befund erklärte die Medianstellung des linken Stimmbandes durch Druck des Aneurysma auf den linken Recurrens, die nur mittelst Einführung der Königschen Kanüle schwindenden Atembeschwerden ließen auf eine tief liegende Stenose der Luftröhre schließen. Beide Annahmen bestätigte die Sektion. Die Figur I zeigt das Röntgenbild mit dem Aortenaneurysma und der eingeführten Königschen Kanüle in situ, die Kanüle passierte die vom Aneurysma bedingte Stenose der Luftröhre knapp oberhalb der Bifurkation und beseitigte die Atembeschwerden. Die Figur 2 illustriert den Durchbruch des Aneurysma 


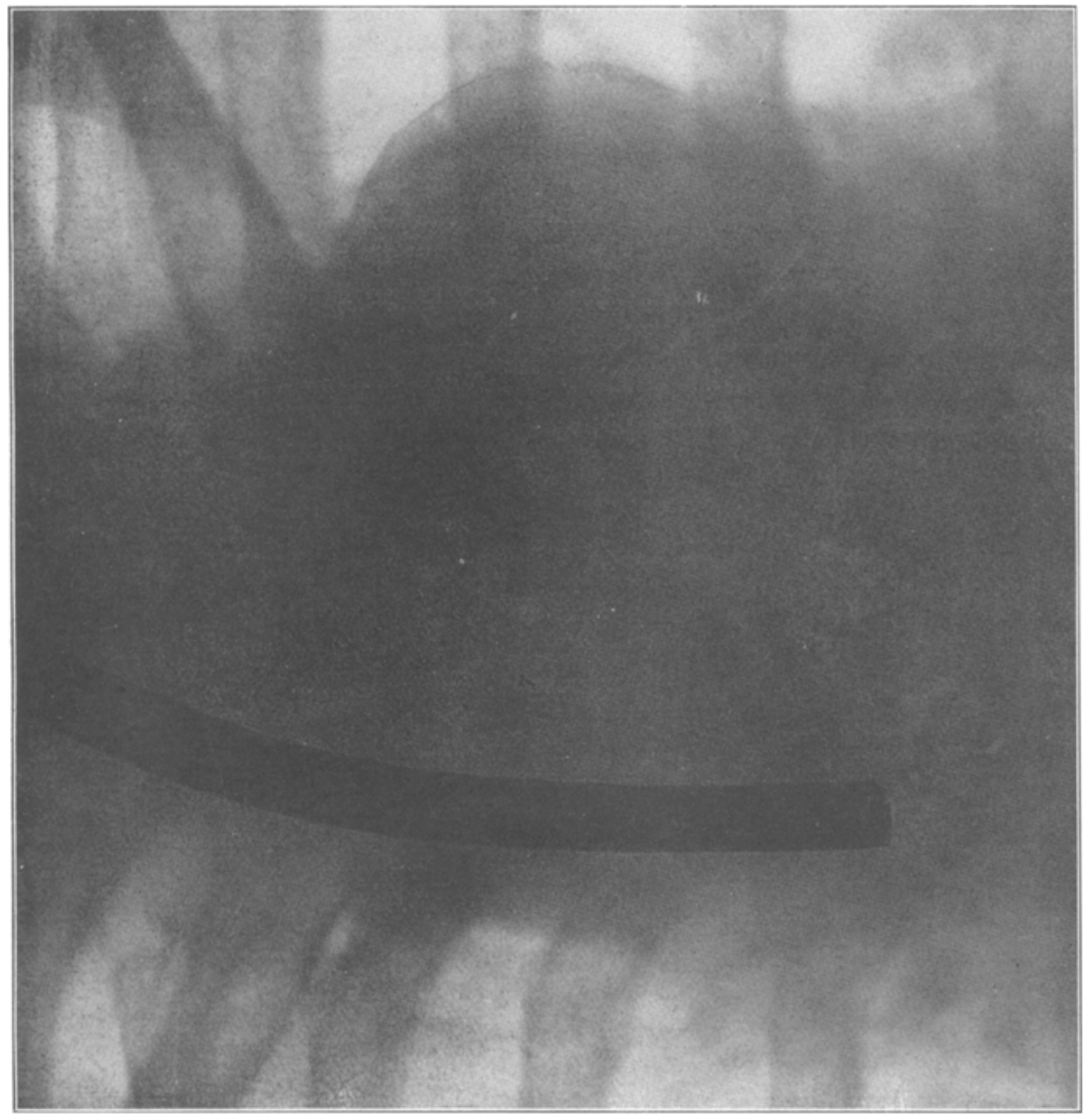

Abb. I. Röntgenbild. Das Aneurysma aortae mit der eingeführten Königschen Kanüle in situ.

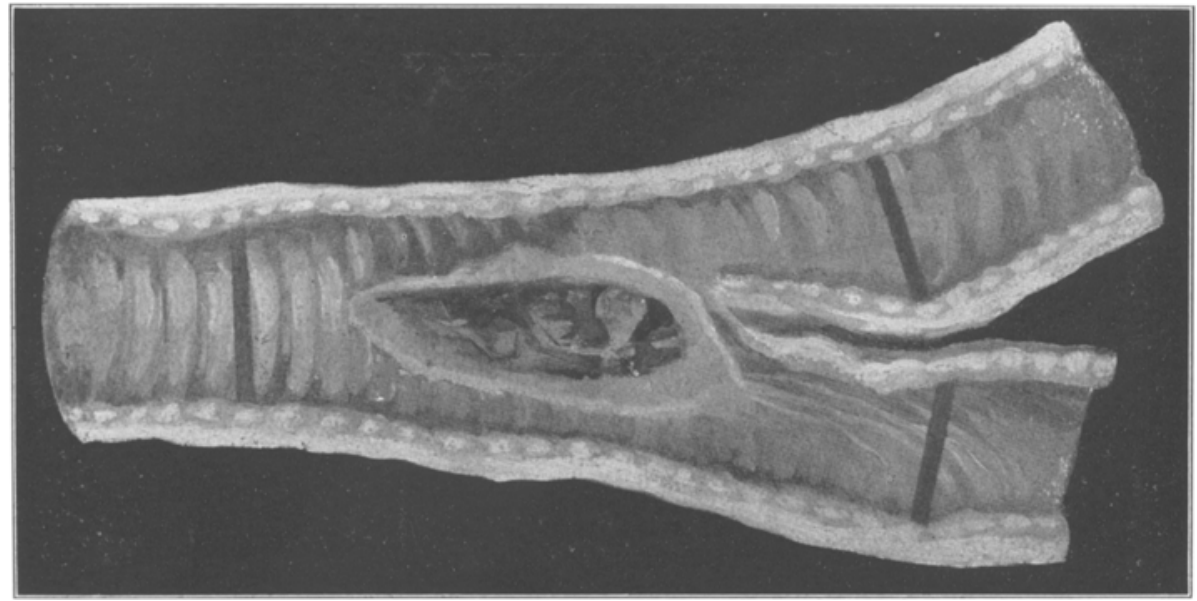

Abb. 2. Durchbruchsstelle des Aneurysma in die Luftröhre. 
56 A. ÓNODI, Medianstellung des linken Stimmbandes, Stenose der Trachea usw.

in die Luftröhre oberhalb der Bifurkation, an dieser Stelle verengte das Aneurysma die Luftröhre und verursachte die Atembeschwerden.

Die histologische Untersuchung des linken Rekurrensstammes zeigte neben den intakten Nervenfasern auch degenerierte Fasern und diesem Befund entsprechend waren in den Posticusnerven mehr degenerierte und wenige intakte Nervenfasern zu sehen. Dieser nekroskopische Befund erklärt die Medianstellung des linken Stimmbandes als infolge der Posticuslähmung eingetretene sekundäre Kontraktur der antagonistischen Verengerermuskeln. 